\title{
The role of advertising and promotions in enhancing brand credibility and customers' using intention
}

\author{
Zahra Seyed Ghorban
}

\begin{abstract}
The antecedents of brand credibility have not been investigated in detail to find out what are the factors that influence brand credibility especially in service industry. Marketing mix elements is one of the factors that have been argued to be potential drivers of brand credibility. This study by targeting this issue tried to find out the significant relationship of advertising, monetary, and non-monetary promotions with brand credibility, which would result in higher expected utility among consumers by increasing quality perception, and decreasing perceived risk and information costs. SEM using AMOS developed to analyze the 177 data collected from consumers who were the users of telecommunication services. The results showed that both advertising and non-monetary promotions were in positive significant relationship with brand credibility, while the relationship between monetary promotions and brand credibility could not be supported. On the other hand, brand credibility was found to be positively related to perceived quality and information costs saved, and negatively to perceived risk; which would result in higher using intention.
\end{abstract}

Keywords: Brand credibility, Information costs saved, Marketing mix elements, Perceived quality, Perceived risk, Utility intention.

\section{Introduction}

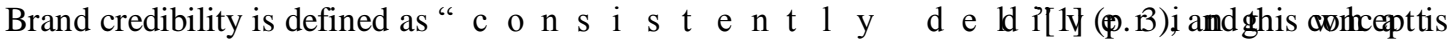
believed to bear two dimensions as trustworthiness, which refers to the willingness, and expertise, which refers to the capability of a brand to deliver what is promised [2]. While the notion of brand credibility has been investigated in the marketing literature and shown to be a significant driver of buying behaviors among customers [e.g. 3], the antecedents of this concepts have not been thoroughly addressed so far, which calls for further examination.

Following what Erdem and Swait [2] conceptualized as brand credibility and found significant relationship between brand investment and brand credibility, the logical inference would lead to the proposition of the significant relationships of marketing mix efforts with brand credibility, since they explicitly mentioned brand investment as how brand spends money on sales, advertising, etc. They argued that marketing mix

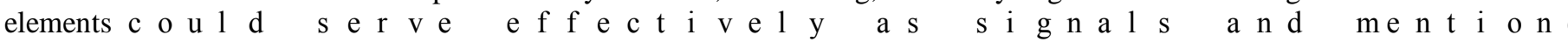
advertising, and warranties not only provide direct product information but also convey indirect information on

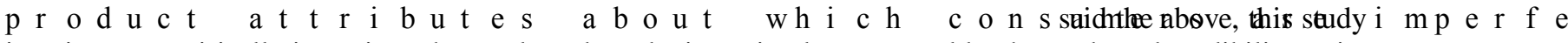
is going to empirically investigate how selected marketing mix elements could enhance brand credibility as its first objective.

Brands could serve as market signals and based on cognitive psychology approach, reduction in uncertainty and information costs, and enhancement in respective confidence in the claims made by brands are the consequences of brand credibility in which they would result in higher expected utility by consumers [2]. Therefore, we are going to investigate the above arguments in a context other than those that have been examined so far to see if they hold true. This will contribute to the second objective of this study by empirically analyzing the consequences of brand credibility in a telecommunication industry in a non-western society as Malaysia, since no study has adopted the framework we proposed for the current study in this region.

\subsection{Marketing mix strategy:}

\section{Literature review}

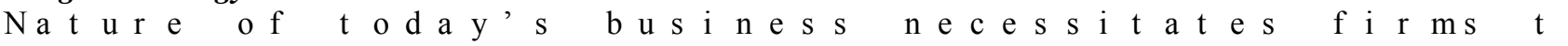
competitive in their respective market environment. One of these strategies is called marketing mix efforts initially called 4 Ps, product, price, place, and promotion [4]

One of the primary activities of marketing mix efforts is advertising, which has been investigated and examined in the branding literature, and it has been demonstrated to positively influence brand equity, brand attitude, brand image, etc. [5-7]. Based on the discussion that the market is characterized by imperfect ad asymmetric information between firms and customers, brand can act as a signal to avoid such information inconsistencies between firms and customers. Erdem and Swait [2] $\mathrm{n}$ o t e d “ $\mathrm{Cr}$ e d i b i l i t y

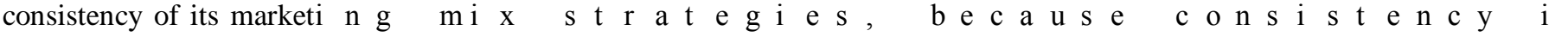


wi l l i n g n e s s a n d a b i l i t y

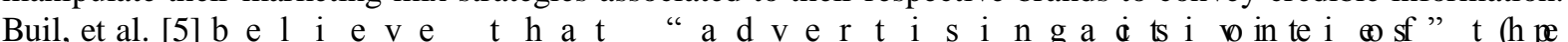
examined and supported that advertising positively influence perceived quality, brand awareness, and brand association. Therefore, advertising, as one of the marketing mix strategies, could be argued to positively influence brand credibility in order to overcome the asymmetric and imperfect nature of information. Thus, it is hypothesized that:

H1: Advertising positively influences brand credibility.

Promotion, as one of the other effective marketing mix strategies, has been discussed and examined to be significant in branding literature. Buil, et al. [5] empirically examined and supported that non-monetary promotion positively influence perceived quality, brand awareness, and brand association as well. They also proposed that monetary promotion would negatively influence perceived quality, brand awareness, and brand association, but this was not supported empirically. Based on the Erdem and Swait [2] that firms could control and manipulate their marketing mix strategies to convey credible information regarding their respective brand to overcome the asymmetric and imperfect nature of information, we, then proposed that non-monetary promotion would positively influence brand credibility and monetary promotion would negatively influence brand credibility. Thus, we hypothesized the following:

H2: Non-monetary promotion positively influences brand credibility.

H3: Monetary promotion negatively influences brand credibility.

\subsection{Brand credibility and using intentions:}

When people as customers are uncertain about the products or services provided by the firms, the brand credibility could help them to distinguish the right information and claims from the wrong ones. Since customers are not as much aware about the products and services provided as the firms, the brand credibility would avoid imperfect information and assist firms to stay away from the asymmetric nature of information about their products and services [2]. Based on the signaling theory [8], when consumers are not certain about the products or the services attributes, this theory suggests that credibility is a key determinant of a particular

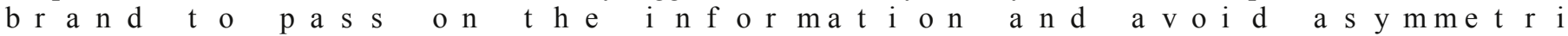
seller can take to convey information credibly about unobservable product quality to the $\mathrm{b} u$ y $\mathrm{k9}$ k. Erdem and Swait [2] considered the brand as a signal that can convey the credible information about the products and services, and would enable the firms to overcome the asymmetric nature of the information that might be f 1 owing be twe e $n$ c us $t$ o me r a n f f i ms. As $t$ he y present marketing mix strategies and activities associated with that brand. In other words, a brand becomes a s i g a l b e c a u e i t e mbodi e s ( o r s y mbolires) a f i $\mathrm{r}^{\prime} \mathrm{s}$ The notion of brand credibility was first conceptualized by Erdem and Swait [2]. " $\quad \mathrm{T} \mathrm{h}$ e $\quad$ b r a n d $\quad$ c $\mathrm{r}$ e (i.e., the credibility of a brand as a signal) is defined as the believability of the product position information

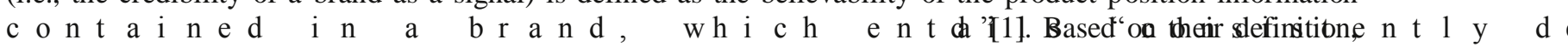
brand credibility has two dimensions: trustworthiness and expertise. Trustworthiness refers to the willingness and expertise refers to the capability of the brand to deliver what it has promised $[1,10]$, failing to do so would gradually wear away the brand equity.

Scholars have investigated brand credibility in product market extensively $[1,10,11]$, and some tried to examine this concept in service markets [12,13], but the antecedents of brand credibility have not been fully addressed so far especially in service industry. Baek and King [12] found that brand credibility strongly influences the using intention by increasing perceived quality, perceived value for money, and information costs saved, and by decreasing perceived risk across multiple service categories. Erdem and Swait [10], by studying the effect of brand credibility on brand consideration and choice, found that brand credibility increases probability of inclusion of a brand in the consideration set, and brand choice conditional on consideration. Baek, et al. [3] examined the brand credibility and brand prestige in consumer brand choice and found that both brand credibility and brand prestige positively influence brand using intention through perceived quality, information costs saved, and perceived risk under different product categories representing the high and low self-expressive nature.

As mentioned, “b r a nds a s c r e di b l e $\mathrm{s}$ i g n a 1 ma $\mathrm{y}$ information processing costs both directly (by providing less costly information) and indirectly (by reducing perceived risk) [2].

Based on the inability of consumers to readily assess the quality of a particular service or product, the need for a mechanism that enables firms to credibly inform consumers regarding the quality level of their 
services or products rise. When a particular brand is considered as credible, this would serve as that kind of mechanism to enhance the quality perception among consumers, which would result in higher utility intention. The consequences of brand credibility have been investigated in both products and services industries $[2,3,12]$ and it has been found that brand credibility for a particular brand is positively related to using intention of that brand through perceived quality, perceived risks, and information costs saved [3, 12].

Based on the above discussions, we propose the following hypotheses to be examined in telecommunication industry in a non-western country:

H4: Brand credibility positively influences perceived quality.

H5: Perceived quality positively influences the brand using intention.

H6: Brand credibility positively influences information costs saved.

H7: Information costs saved positively influence the brand using intention.

H8: Brand credibility negatively influences perceived risk.

H9: Perceived risk negatively influences the brand using intention.

\subsection{Sample:}

\section{Method:}

This study was conducted in Kuala Lumpur, Malaysia, and MBA students in three different public universities (UM, UKM, and UTM City Campus) in this city were requested to participate. Since at least 2 years pre-admission working experiences are required for those who wish to study MBA in these three public universities, this makes these participants a better population to study. International students were excluded from this study since local students are much more familiar with those companies that operate in communication sector, which provides telephone services. This study targets only those companies that provide SIM cards and broadband (e.g. Maxis, Digi, Celcom, etc.) services to customers. The numbers of 250 sets of questionnaires were distributed among those students in which we received 189 sets. After reviewing the data collected, 12 were dropped due to incomplete or inconsistent responses. Consequently 177 sets of questionnaires were u t i l i z e d f or the a nal ys i s. The first part of (gender, age, and the name of the service provider they have used recently), and the second part contains the 26items to measure the variables included in this study.

\subsection{Measurement instruments:}

The 9-items developed by Yoo, et al. [7] were utilized to measure advertising ( $\alpha=$, rlofletary ( $\alpha=$.and Qol)monetary promotion ( $\alpha=$. Oahor scholars have used this measurement instrument to examine these concepts in branding literature [e.g. 5]. The 17-items developed and examined by Erdem and Swait [2] were utilized to measure brand credibility ( $\alpha=$, pertel)ved quality ( $\alpha=$, per(ee) $)$ ved risks ( $\alpha=, 96$ ) information costs saved ( $\alpha=$, ald6using intention ( $\alpha=$. These)items have been applied to measure these concepts in the product and service industry and they have been shown to be reliable and valid measurement instruments for this purpose [e.g. 12,13].

All of the items included in this study were measured using 9-p o i n t $\mathrm{s}$ c a 1 e s $\mathrm{f} \mathrm{r}$ o $\mathrm{m}$

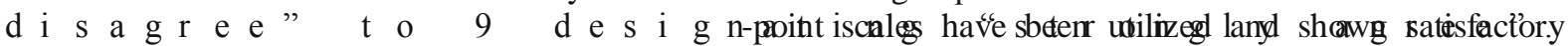
validation to measure brand credibility, perceived quality, perceived risks, information costs saved, and using intention in different studies [1-3, 10]. We follow the same nine-point scales to measure the instrument we develop to measure advertising, monetary and non-monetary promotion.

\subsection{Reliability and validity:}

Both Confirmatory Factor Analysis (CFA) and Convergent and Discriminant validity were performed in this study to establish the construct validity of the variable included in this study to be able to include them in hypotheses testing procedure.

Structural Equation Modeling (SEM) using Amos with maximum likelihood estimation were utilized to perform the Confirmatory Factor Analysis (CFA) in order to validate the model proposed in this study. One of the criteria to establish overall model fit for the proposed model is chi-square, but scholars have discussed that the overall model could be easily rejected if the number of samples is large [14-16]. Therefore, this study attends to both the magnitude of chi-square and other fit indices. All of the variables in this study established statistically good model fit. Goodness of fit index (GFI), normed fit index (NFI), comparative fit index (CFI), incremental fit index (IFX), and relative fit index (RFI) were all examined to be more than .90 that is acceptable limit for these indices. Almost all root mean residuals (RMR) were less than or close to .05 , and all the standard root-mean square error of approximation (RAMSEA) were less than or close to .10, which all of the above indices indicate a good fit for each of the constructs. 
The role of advertising and promotions in enhancing brand credibility and customersö

Using intention

\begin{tabular}{|c|c|c|c|c|c|c|c|c|c|}
\hline Variables & $\chi^{2}$ & $\mathrm{df}$ & $\chi^{2} / \mathrm{df}$ & GFI & NFI & CFI & RMR & RMSEA & Loadings \\
\hline $\mathrm{AD}$ & 6.093 & 5 & 1.219 & .99 & .99 & 1.00 & .014 & .030 & All>.84 \\
\hline NMP & .185 & 2 & .912 & 1.00 & 1.00 & 1.00 & .003 & .000 & All $>.83$ \\
\hline MP & 11.589 & 5 & 2.318 & .98 & .99 & .99 & .017 & .075 & All>.85 \\
\hline BC & 20.379 & 14 & 1.456 & .98 & .99 & .99 & .013 & .044 & All> .85 \\
\hline PQ & 6.960 & 5 & 1.392 & .99 & .99 & .99 & .013 & .041 & All >.88 \\
\hline PR & 16.848 & 20 & .842 & .98 & .99 & 1.000 & .016 & .000 & All $>.82$ \\
\hline ICS & 3.629 & 2 & 1.815 & .99 & .99 & .99 & .012 & .059 & All>.86 \\
\hline UI & \multicolumn{8}{|c|}{ Saturated Model } & All> $>87$ \\
\hline
\end{tabular}

AD: Advertising; NMP: Non-monetary Promotion; MP: Monetary Promotion; BC: Brand Credibility; PQ: Perceived Quality; PR: Perceived Risk; ICS: Information Costs Saved; UI: Using Intention

\subsection{Convergent and Discriminant validity:}

As shown in table 2 all variables in this study reached satisfactory level in both convergent and discriminant validity. For establishing convergent validity average variance extracted (AVE) should exceed .50 [17]. With regard to discriminant validity, as shown in table 2, the maximum shared squared variance (MSV) and average shared squared variance (ASV) should both be less than average variance extracted (AVE) in order to establish the discriminant validity [18]

Table 2: Convergent and Discriminant Validity

\begin{tabular}{lccc}
\hline Constructs & AVE & MSV & ASV \\
\hline Advertising Spend & .748 & .573 & .290 \\
Monetary Promotion & .744 & .564 & .233 \\
Non-Monetary Promotion & .826 & .573 & .303 \\
Brand Credibility & .721 & .501 & .341 \\
Perceived Quality & .926 & .728 & .323 \\
Information Costs Saved & .895 & .697 & .328 \\
Perceived Risk & .886 & .514 & .244 \\
Using Intention & .854 & .728 & .366 \\
\hline
\end{tabular}

Note: $\mathrm{N}=177$

III. Results:

Table 3 shows the mean, standard deviation and the correlation of the variables included in this study. Almost all correlation reached significant level $p<.01$, which indicates that all of the hypotheses developed in this study were empirically supported. 
Table 3: Correlation Analysis

\begin{tabular}{lcccccccccc}
\hline Variable & Mean & SD & 1 & 2 & 3 & 4 & 5 & 6 & 7 & 8 \\
\hline 1. Advertising Spend & 6.82 & 1.79 & 1 & & & & & & & \\
2. Monetary Promotion & 6.93 & 1.61 & $.56^{* *}$ & 1 & & & & & \\
3. Non-Monetary Promotion & 7.13 & 1.68 & $.69^{* *}$ & $.69^{* *}$ & 1 & & & & \\
4. Brand Credibility & 7.02 & 1.57 & $.65^{* *}$ & $.54^{* *}$ & $.66^{* *}$ & 1 & & & \\
5. Perceived Quality & 7.30 & 2.13 & $.36^{* *}$ & $.23^{* *}$ & $.35^{* *}$ & $.49^{* *}$ & 1 & & \\
6. Information Costs Saved & 6.87 & 1.98 & $.40^{* *}$ & $.36^{* *}$ & $.33^{* *}$ & $.56^{* *}$ & $.65^{* *}$ & 1 & \\
7. Perceived Risk & 2.92 & 2.22 & $-.26^{* *}$ & $-.19^{*}$ & $-.32^{* *}$ & $-.36^{* *}$ & $-.66^{* *}$ & $-.57^{* *}$ & 1 & \\
8. Using Intention & 7.29 & 1.92 & $.36^{* *}$ & $.25^{* *}$ & $.32^{* *}$ & $.50^{* *}$ & $.81^{* *}$ & $.80^{* *}$ & $-.68^{* *}$ & 1 \\
\hline
\end{tabular}

**Significant at $p<.01$ (two-tailed); * Significant at $p<.05$ (two-tailed)

In order to test the hypotheses in this study Structural Equation Modeling (SEM) using AMOS 18.0 with maximum likelihood estimation was developed. The following table (Table 4) shows the standardized path coefficient. As it is shown all path coefficients are significant indicating that the proposition and hypotheses are all supported. The overall model fit shows satisfactory fit indices $\left[\chi^{2}=419.996, d f=287, \chi^{2} / d f=1.463\right.$; GFI= $.85 ; \mathrm{CFI}=.97 ; \mathrm{NFI}=.92 ; \mathrm{RMSEA}=.051]$.

Table 4: Paths coefficient and critical ratio values

Paths Hypotheses Path Coefficients CR

\begin{tabular}{llcc}
\hline Advertising Spend $\Rightarrow$ Brand credibility & H1: Supported & $.40^{* * *}$ & 4.00 \\
Non-Monetary promotion $\Rightarrow$ Brand credibility & H2: Supported & $.33^{* *}$ & 2.82 \\
Monetary promotion $\Rightarrow$ Brand credibility & H3: Not Supported & .08 & .866 \\
Brand credibility $\Rightarrow$ Perceived Quality & H4: Supported & $.55^{* * *}$ & 7.41 \\
Brand credibility $\Rightarrow$ Information Costs Saved & H5: Supported & $.61^{* * *}$ & 8.39 \\
Brand credibility $\Rightarrow$ Perceived Risk & H6: Supported & $-.43^{* * *}$ & -5.66 \\
Perceived Quality $\Rightarrow$ Using Intention & H7: Supported & $.52^{* * *}$ & 10.86 \\
Information Costs Saved $\Rightarrow$ Using intention & H8: Supported & $.50^{* * *}$ & 10.39 \\
Perceived Quality $\Rightarrow$ Using intention & H9: Supported & $-.19^{* * *}$ & -.4 .38 \\
\hline
\end{tabular}

$* * * p<0.001, * * p<0.005$

Each path coefficient was examined to be statistically significant $(p<0.001$ or $p<0.05)$ in its predicted direction except the path from monetary promotion to brand credibility. As shown in the above table, advertising and non-monetary promotions were found to positively influence brand credibility supporting hypotheses 1 and 2. Hypothesis 3 could not be supported. Brand credibility was found to positively influence perceived quality and information costs saved, and negatively influence perceived risk supporting hypotheses 4 , 5, and 6. Perceived quality and information costs saved were found to positively influence using intention supporting hypothesis 7 and 8 , and perceived risk was found to negatively influence using intention supporting hypothesis 9 . Figure 1 shows the hypothetical path values for this study. 


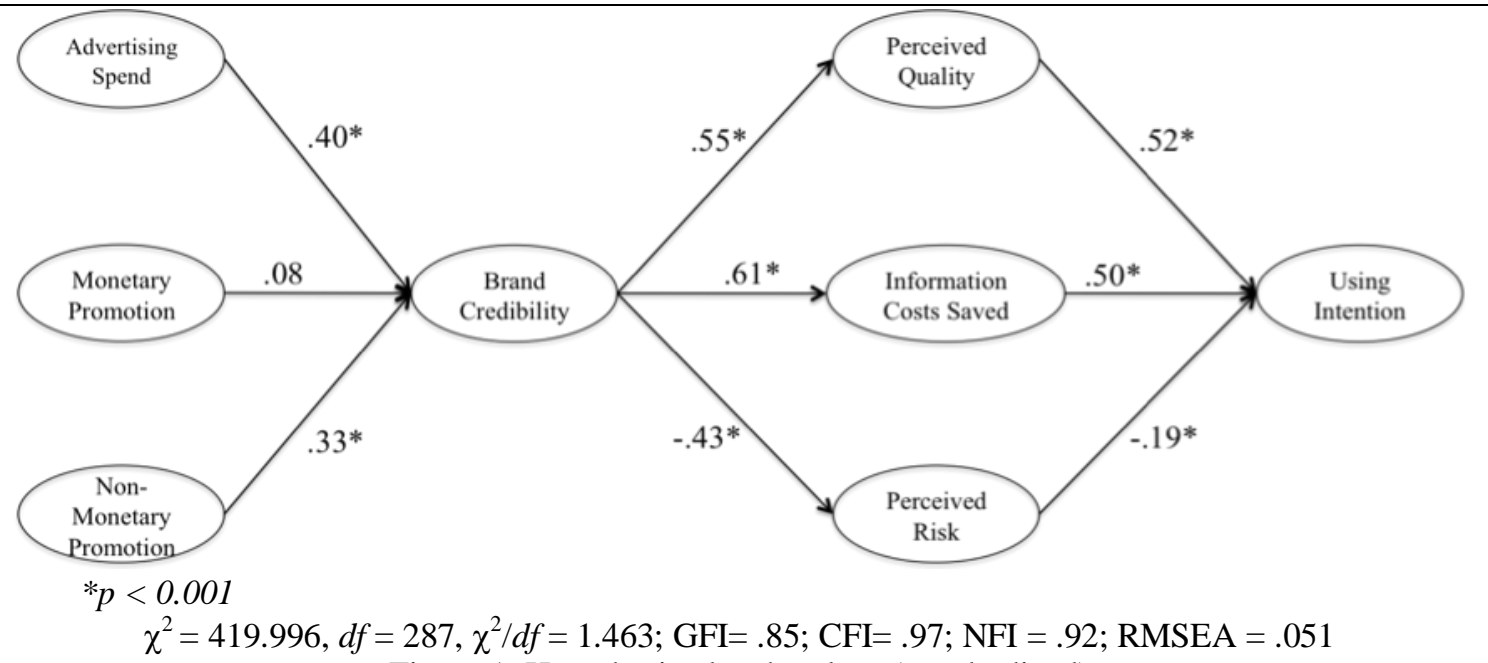

Figure 1: Hypothesized path values (standardized)

\section{Conclusion:}

This study was set out to address the issue of brand credibility conceptualized by Erdem and Swait [2] in different context than those studied so far in order to establish the applicability of the proposed model. The first objective of this research was to examine the relationships between marketing mix elements and brand credibility to find out if they serve as antecedents to the latter concept based on the arguments provided by Erdem and Swait [2] that brand investment is a significant driver of credibility. This study contributed to this issue by empirically examining these drivers in a service industry.

On the other hand arguments have been made regarding the ability of brand credibility to 1) elevate the c ons umers, perception a bout a qual i t y of a brand, associated to information gathering and information processing, in which would result in higher expected utility by consumers. These sequence of relationships have been studied in mostly western context and in product categories in particular in which this study apply the model in a service market in a non-western country to find out if the previously found relationships would still hold true, which formed another important contribution of this study.

The results elaborated in the previous section demonstrate that not all marketing mix elements could enhance the credibility of a brand as monetary promotion was found to be in an insignificant relationship with brand credibility. But as proposed for other marketing mix elements, advertising and non-monetary promotion were found to be in significant relationships with brand credibility indicating that these efforts would lead to higher level of brand credibility. This is consistent by what Erdem and Swait [2] conceptualized as brand investment. Advertising and non-monetary promotions, as one of the controlled communications strategy in service marketing, are argued to increase satisfaction, attitudes, and reuse intention among consumers [19]. On the other hand these elements could be used to serve as tangible information and meaning ascribed to a brand to enhance the credibility level in which it would result in reducing risk and higher utility intention.

The implications of this study are twofold. First, I suggest that the marketing mix elements are important drivers of brand credibility and extending the model proposed in service markets. Based on the signaling theory [8], it could be inferred that marketing mix elements could serve as both direct and indirect information provider [2] for consumers that could only become fully aware of a particular service when they have used it already. Consistent with previous discussion on the role that marketing mix elements play in providing reliable information $[2,12]$, this study established these significant relationships in a particular service market. The insignificant relationship of monetary promotion with brand credibility could be attributed to the argument that monetary promotion would harm the brand since they are too short to influence the brands [20]; and consumers regards it as not a positive impact on the credibility level of the brands.

The second theoretical implication inferred from this study is the generalizability of the model proposed for brand credibility into a service market such as telecommunication industry in a non-western context. Therefore, this study provides more insights and support the role brand credibility plays in enhancing e $x$ p e c t e d u t i l i t y a mo $\mathrm{ng}$ c o $\mathrm{n} \mathrm{s} \mathrm{u} \mathrm{me} \mathrm{ronswithbregardatothe} \mathrm{quanity} \mathrm{ataimed}$ by brands, b) lowering the associated risks, and 3) lowering the costs required to gathering and processing information.

Managerial contribution of this study includes providing support for the significant role of marketing mix elements, namely advertising and non-monetary promotions, in enhancing brand credibility in which managers in different service industries should bear this in mind that the activities associated with the marketing 
of their services have important effect on the way their brands are considered as being capable and willing to consistently deliver what they promise.

Secondly, since this study has provided insights for the applicability of the proposed model of brand credibility and how it would increase the expected utility, this would assist managers in service industry to understand that the signals received by consumers are critical in their decision to engage or reuse the services of a particular brand. Credible brands are intend to have more consumers engaging to the buying and using behavior by providing credible information, which decrease the associated costs to gather and process the required information for consumers that are not able to have the reliable information until they start using the service, increasing the quality perceived, and decreasing the associated risk of engaging to buying behavior.

This study could only focused on one particular service industry as telecommunication. Future studies could address the issues discussed in the present research in different service categories, since there is still room for extending the present arguments. For instance, utilitarian and hedonic services could be investigated based on the role marketing mix elements could play in improving the brand credibility, which would be reexamined to see if the latter could also bring greater expected utility.

This study used student sample to conduct empirical investigation. Even great concerns were taken into consideration to choose a service market that students would mostly use, future studies could replicate the model examined in this study using non-student samples.

\section{References}

1. Erdem, T., J. Swait, and J. Louviere, The impact of brand credibility on consumer price sensitivity. International Journal of Research in Marketing, 2002. 19(1): p. 1-19.

2. Erdem, T. and J. Swait, Brand Equity as a Signaling Phenomenon. Journal of Consumer Psychology, 1998. 7(2): p. 131-157.

3. Baek, T.H., J. Kim, and J.H. Yu, The differential roles of brand credibility and brand prestige in consumer brand choice. Psychology and Marketing, 2010. 27(7): p. 662-678.

4. Kotler, P., Marketing Management. 11th ed2003, Upper Saddle River, NJ: Prentice- Hall.

5. Buil, I., L. de Chernatony, and E. Martinez, Examining the role of advertising and sales promotions in brand equity creation. Journal of Business Research, 2011(0).

6. Kim, J. and Y.J. Hyun, A model to investigate the influence of marketing-mix efforts and corporate image on brand equity in the IT software sector. Industrial Marketing Management, 2011. 40(3): p. 424-438.

7. Yoo, B., N. Donthu, and S. Lee, An examination of selected marketing mix elements and brand structure. Journal of the Academy of Marketing Science, 2000. 28(2): p. 195-211.

8. Spence, M., Market Signaling: Informational Transfer in Hiring and Related Screening Processes 1974, Cambridge, MA: Harvard University Press.

9. Rao, A.R., L. Qu, and R.W. Ruekert, Signaling unobservable product quality through a brand ally. Journal of Marketing Researc, 1999. 36(2): p. 258-68

10. Erdem, T. and J. Swait, Brand Credibility and its Role in Brand Choice and Consideration. Journal of Consumer Research, 2004. 31(1): p. 191-199.

11. Spry, A., R. Pappu, and T.B. Cornwell, Celebrity endorsement, brand credibility and brand equity. European Journal of Marketing, 2011. 45(6): p. 882-909.

12. Baek, T.H. and K.W. King, Exploring the consequences of brand credibility in services. Journal of Services Marketing, 2011. 25(4): p. $260-272$.

13. Sweeney, J. and J. Swait, The effects of brand credibility on customer loyalty. Journal of Retailing and Consumer Services, 2008. 15(3): p. 179-193.

14. Bentler, P.M. and D.G. Bonett, Significance tests and goodness-of-fit in the analysis of covariance structures. Psychological Bulletin, 1980. 88(588-600).

15. Marsh, H.W., J.R. Balla, and R.P. McDonald, Goodness-of-fit indexes in confirmatory factor analysis: The effect of sample size. Psychological Bulletin, 1988. 103(391-410).

16. Marsh, H.W. and D. Hocevar, Application of confirmatory factor analysis to the study of self-concept: First-and higher-order factor models and their invariance across groups. Psychological Bulletin, 1985. 97(562-582).

17. Fornell, C. and D.F. Larcker, Evaluating structural equation models with unobservable and measurement errors. Journal of Marketing Research, 1981. 18: p. 39-50.

18. Hair, J., et al., Multivariate data analysis. 7th ed2010, Upper Saddle River, NJ: Prentice Hall, Inc.

19. $\mathrm{Gr}$ a c e , D. a Exadnining the effect Cofi sersice brand communications on brand evaluation. Journal of Product \& Brand Management, 2005. 14(2): p. 106-16.

20. Winer, R.S., A reference price model of brand choice for frequently purchased products. Journal of Consumer Research, 1986. 13(September): p. 250-6. 